\title{
Research on the Significance of Electronic Integrated Graphic Teaching Method for High School English Writing
}

\section{Xuqiu Tang}

School of Foreign Language, China West Normal University, Nanchong, Sichuan, China

\begin{abstract}
English writing, as a must-learn content for English learning and one of the five major language skills, is an important reflection of students' ability in language output, and has become the focus of English teaching in high schools. However, there are still problems in the teaching of English writing. It has become an important issue that need to be studied about how to further improve students' writing efficiency and writing quality, and further improve their English writing ability. The electronic integrated graphic teaching method is based on graphic theory under the development of modern information technology. This article briefly explains the electronic integrated graphic teaching method, and specifically analyzes the application of this teaching method for the teaching of English writing.
\end{abstract}

Key words: information technology; graphic theory; English writing; E-learning

\section{Introduction}

The General Senior High School English Curriculum Standard (2017 Edition) states that as a course for the learning and using of English. It is linked with the compulsory education curriculum, aims to lay a good foundation for students to continue to learn English and develop for life (Ministry of Education of the People's Republic of China 2018). Language learning has gone through the process from input to output. The learning of comprehension skills prepares the language for input, while the learning of expressive skills provides the possibility for language output. Writing, as an expressive skill in the five major language skills of high school English, has great significance in language output. The improvement of writing also lays a good foundation for students' continuing learning of English and lifelong development. The use of electronic integrated graphic teaching method for English writing teaching is one of the methods of combining modern educational methods with the latest information-based teaching resources and methods for writing teaching, which will significantly influence students' writing learning.

\section{Electronic Integrated Graphic Teaching Method}

The development and widespread application of the Internet, especially the technology of mobile Internet, has provided new technological means for educational modernization and has unprecedentedly changed people's learning content, learning methods and learning habits (Wang Shaojie, Sun Haixia 2019). The electronic integrated graphic teaching method is a teaching method combining electronic information technology with graphic, like some pictures and mind maps (Cao Lijuan, Guo Shudong 2019). It is a teaching method of classroom presentation with the help of information technology and a new attempt and development of English teaching in the era of the Internet Plus. According to the

Copyright (C) 2020 by author(s) and Frontier Scientific Research Publishing Inc.

This work is licensed under the Creative Commons Attribution International License (CC BY 4.0).

http://creativecommons.org/licenses/by/4.0/ 
definition, this teaching method can be decomposed into two parts to define: electronics and graphic teaching methods. Electronics is a series of information products available in computer applications under the development of modern information technology. And when applied to teaching, it refers to the tool which uses modern teaching methods and means for teaching, such as electronic courseware, pictures, audio, video, and so on. Electronics incorporates information technology to improve the traditional teaching method of word of mouth by teachers. It fully reflects the characteristics of using electronic information technology for teaching, and also provides convenience for teaching, which increases the teaching space. And also the vision of students is no longer limited to the vision owned by teachers, but a wider world. Students can practice and review repeatedly from the Internet. Graphic teaching method is a teaching method, which was developed on the basis of graphic theory. Graphic theory is different from other learning theories, for example, the theory of behaviorism can only explain behavior, however, schema theory can be used to interpret any learning experience (Wei Han, Zhang Baicheng, 2004). It not only provides the possibility for the development of graphic theory for graphic teaching methods, but also provides a basis for the combination of graphic teaching methods and electronic information technology.

The electronic integrated graphic teaching method is a modern teaching method which uses computer technology to successively click on a line segment or frame, corresponding text and various symbols to indicate the time, space, and causality and development trend (Shi Zhengwen, 2003). The key to carry out the teaching method is to clarify the context, and then design a linear knowledge framework such as points, lines, and areas to help students further sort out logical relationships and organize knowledge. And applied to English writing teaching, you can use this idea to optimize and improve English teaching. With the help of the theoretical support of illustration, it is applied to all the stages of English writing. Teachers can use picture processing and pictures to help students further clarify the writing framework, organize writing ideas, and fill in written content.

\section{The Rationality of Electronic Integrated Graphic Teaching Method Applied in English Writing Teaching}

3.1 The meeting of the requirements of the Curriculum Standard of English for Senior High School

The Curriculum Standard of English for Senior High School (2017 Edition) pointed out that the general high school English curriculum should pay attention to the reform of teaching mode and learning method in the context of modern information technology, make full use of information technology, promote the deep integration of information technology and curriculum teaching, enrich the curriculum resources, and expand learning channels (Ministry of Education of the People's Republic of China, 2018). According to the requirements of the new curriculum standards, we must fully integrate modern information technology methods to achieve resource integration while striving to innovate teaching methods and student learning methods. This provides a broad development space for teachers to actively learn and introduce new teaching methods in teaching. It also provides the possibility of applying the electronic integrated graphic teaching method to the teaching of high school English writing.

In terms of language skills, "viewing" language skills have been added to the The Curriculum Standard of English for Senior High School (2017 Edition). With the development of information technology, the demand for the ability to interpret and understand graphics, tables, animations, symbols and videos has been increased. Therefore, students should develop the ability of viewing in this area and learn to understand and analyse the multimedia discourse in daily learning. The electronic integrated graphic teaching method is taught in the form of graphs, through the composition of dots, lines and planes. While training students' logical thinking, it also helps students develop language skills for "viewing". 
3.2 Electronic integrated graphic teaching method is the mutual reference of interdisciplinary teaching method

The electronic integrated graphic teaching method is applied to the history subject, and it is more widely used to grasp some historical events and timeline in the history subject. A method aims to visually reproduce the historical occurrence process and achieve teaching tasks more efficiently. Its focus is on the use of electronic technology to process pictures for contextual organization. It has not been widely used in English teaching, but the first pursuit of interdisciplinary education is to break the limitations of disciplinary barriers on the perspective of scholars (Pang Zhenchao, 2019). Interdisciplinary courses have emerged because of the curriculum innovation. There are many courses, such as: Introduction to Behavioral Finance, which runs through the relevant knowledge modules of nearly 25 traditional courses in the three courses of finance, economics and psychology (Pang Zhenchao, 2019). Therefore, the interdisciplinary courses have helped learning in different fields, and further promoted the development of ideas and the emergence of different thoughts.

The same should be true of the application of teaching. The teaching method not only exists independently for a certain subject, but also innovates and integrates according to the characteristics of the subject. It is neither a simple copy nor a complete change. It is a comprehensive application of its own reasonable application. Electronic integrated graphic teaching method is different from the application of the subject of history. It not only relies on image processing, but on the basis of schema theory, with the help of modern technical means to display, so as to develop high school English teaching writing. Teachers can help students to integrate the concept of writing contents and sort out ideas before writing; students can also supplement and improve the contents during the writing process, and structure the scattered knowledge and contents. Students can continue to adjust the frame structure and try on the contents to achieve multi-manuscript writing.

\section{Application of Electronic Integrated Graphic Teaching Method in High School English}

\section{Writing}

Students have mastered basic language knowledge and cultural background knowledge before writing with the schema theory, so teachers can logically organize writing requirements through electronic integrated graphic teaching method, and use electronic equipment to establish about the structure and framework of writing. Therefore, students can integrate the whole piece of scattered information, and have a more intuitive and clear understanding of the corresponding requirements of the sub-items, which can help students further clarify the overall requirements of writing. There will be no unnecessary interference due to the requirements of the subject during their writing.

Secondly, by sorting out the requirements of the topic, teachers also need to continue to lead students in a simple brainstorming, focusing on the theme of the composition, extending outwards, fully mobilizing the background knowledge in students' minds, using information means to map the mind, etc. Some concepts or ideas appearing in the concept of "cluster" to integrate, connect the concept "cluster" of the students" thoughts into a line to form a complete graphic structure, and further build the network of graphic structures established to sort out the different aspects. Therefore, it forms a combination of point-line-surface to prepare for the framework of writing. The analysis of the frame preparation before writing is analyzed through the electronic integrated graphic teaching method, which helps to mobilize students' existing language icons, and organize the rich but fragmented language knowledge system into the needs of writing. The frame structure is beneficial to students for further language output.

In the writing process, teachers need to re-present the original writing framework, and guide students to consciously use the framework to write. When the teacher is doing writing assessment, he can continue to use the original writing framework to compare the flash points and deficiencies of the contents level of the students in addition to the language knowledge, and select a typical model with a high degree of correspondence with the frame contents. The article will be explained and presented in class, helping students to further compare the parts of their composition that can be improved, 
and then they can write the second draft. If teachers put more emphasis on writing assessment, students will gradually develop a sense of multi-script writing, so as to achieve more than the level of language knowledge itself, and repeated chewing on the contents can also be helpful to the further improvement.

Electronic integrated graphic teaching method is a teaching method combined with modern information technology. On the one hand, it provides technical support for writing teaching; on the other hand, schema theory provides students a basis for writing knowledge. Both of the combination can improve the efficiency of classroom writing teaching and improve students' ability to sort out the structure of writing ideas.

\section{Conclusions}

Writing is very important in high school English teaching. It is one of the important tests to test students' language output ability. Because writing requires high comprehensive ability of students, it is necessary to master various English vocabularies and use a variety of grammar flexibly which is more difficult, and it is a question type where students lose more points in the test (Zhu Yihong, 2019). Therefore, in English teaching, teachers not only need to explain the basic knowledge of English and help students master vocabulary, grammar, pronunciation and intonation, but also need to continuously improve teaching methods in the teaching process with the development of society.

Nowadays, people has entered into the information age, one should cultivate "Internet plus" thinking, use network information resources, and constantly reform the traditional teaching methods to achieve the convenience and diversification of teaching. And it also maximizes the efficient learning of students. On the contrary, if the traditional teaching methods have been maintained without reform or innovation, it will be difficult to keep up with the newly teaching methods and meet students' needs.

The electronic integrated graphic teaching method conforms to the development of information technology and innovates the teaching methods. Writing is a headache for students in their English learning, but the framework of the writing contents will be more clear by combing the framework and clarifying the structure. It can not only help students improve writing efficiency to a certain extent, but also help to overcome students' fear of writing. However, it needs further investigation and more experiments to investigate its application and function. The reform and innovation of teaching methods are already on the way, and teachers can continue to optimize teaching methods while teaching, in order to further promote teaching.

\section{Conflicts of Interest}

The author declares no conflicts of interest regarding the publication of this paper.

\section{Reference}

[1] Cao L.J, Guo S.D. (2019). The Application of Electronic Integrated Teaching Method Illustrated in Junior High School History Teaching -- A Case Study of to the Imperial Examination System (in Chinese). Chinese Educational Technology and Equipment Press, (11): 111-112.

[2] Pang Z.C. (2019). The "Road" of Teaching Reform in Interdisciplinary Education (in Chinese). University Education Science, (04): 53-58.

[3] Shi Z.W. (2003). The Application of the Electronic Integrated Graphic Teaching Method in the Teaching of the History (in Chinese). China Educational Technology, (08): 45-46.

[4] Wei H., Zhang B.C. (2004). Review and Prospect of Schema Theory and Research on Foreign Language Teaching in China. Journal of Xi'an International Studies University, (03): 63-66.

[5] Wei J.Y. (2018). Research on English Reading and Writing Teaching in Senior High School Based on Schema Theory. Course Education Research, (52): 75. 
[6] Wang S.J., Sun H.X. (2019). An Analysis of College English Teaching Paths Based on "Internet Plus" Thinking. Journal of Tonghua Normal University, 40(12): 123-126.

[7] You X.L., Xue X.X. (2019). The Application of Mind Map from the Perspective of Schema Theory in English Reading Teaching of Senior High School. Basic Foreign Language Education, 21(04): 63-68+107.

[8] Zhu Y.H. (2019). Application of Multimodal Teaching Method in English Writing Teaching in Senior High School. English Square, (12): 162-163.

[9] Ministry of Education of the People's Republic of China. (2018). The General Senior High School English Curriculum Standard. People's Education Press. 